Volume, 14, n. 1, ano, 2018

\title{
ENSINO AO PROEJA POR MEIO DE AULAS PRÁTICAS: MINICURSO "FATORES QUE AFETAM A FOTOSSÍNTESE".
}

Samylla Tassia Ferreira de Freitas,

Leticia Ferreira de Sousa,

Agna Rita dos Santos Rodrigues

Sandra Mara Santos Lemos de Oliveira

Luiz Carlos Ramos dos Santos

\begin{abstract}
RESUMO: A Educação de Jovens e Adultos permite a democratização do ensino, contribuindo para que trabalhadores, muito tempo fora da escola, tenham acesso à educação. Nessa perspectiva, as aulas práticas são vistas como uma opção viável para experimentar as teorias vistas em sala de aula, dar maior significado ao processo de ensino-aprendizagem, considerando o conhecimento prévio que esses alunos trazem consigo. Para tanto, o minicurso "Fatores que Afetam a Fotossíntese" foi ofertado aos alunos do PROEJA Administração durante o estágio supervisionado. Esses alunos tiveram, pela primeira vez, o acesso ao laboratório, bem como aos seus equipamentos, aprendendo, após a ministração de aula teórica, a manuseá-los e a realizar experimentos, garantindo que o conteúdo da teoria fosse observado na prática, valorizando o trabalho em equipe e a contextualização com suas realidades.
\end{abstract}

Palavras-chave: Educação de Jovens e Adultos. Estágio Supervisionado. Laboratório.

\section{THE TEACHING PROEJA THROUGH PRACTICAL CLASSES: SHORT COURSE "FACTORS AFFECTING PHOTOSYNTHESIS"}

\begin{abstract}
The Education for Young and Adult allows the democratization of education and the access of workers who were long out of school. Practical classes are seen as a viable option to experience the studied theories in the classroom, giving more meaning to the learning process and valuing prior knowledge that these students bring with them. Thus, it was offered in supervised internship, the short course "Factors Affecting Photosynthesis" for students of PROEJA Administration. These students have access to laboratory and its equipment for the first time. After the lecture, they could handle the equipments and conduct experiments, ensuring that the contents of the theory were observed in practice, valuing work team and contextualization with their realities.
\end{abstract}

Keywords: Education for young people and adults. Supervised internship. Laboratory.

INTRODUÇÃO 
Volume, 14, n. 1, ano, 2018

O estágio supervisionado em docência proporciona ao acadêmico o contato com a escola, a vivência com os alunos e a oportunidade de articular teoria e prática (BORSSOI, 2008). Para tanto, é preciso caminhar de forma que professores e alunos possam argumentar e discutir as práticas vividas na escola. É necessário levar em conta a diversidade dos alunos, entretanto, é fundamental que o professor, na sua contribuição como mediador de conhecimento, seja dinâmico, inovador e faça uso de analogias, para que o conhecimento avance e o ensino aconteça (ALVES, 1999).

A prática de ensino, por meio do estágio supervisionado, promove o domínio do professor sobre métodos e técnicas (ALMEIDA, 1995). É, portanto, necessário abandonar métodos conservadores, permitindo que professor e aluno interajam no processo de construção e reconstrução do conhecimento (DEMO, 1996).

O PROEJA (Programa Nacional de Educação Profissional Integrada à Educação Básica), instituído pelo Decreto 5.840, de 13 de julho de 2006 (BRASIL, 2006), destina-se à Educação Inicial e Continuada de trabalhadores, tornando mais democrático o acesso ao ensino, visto que, por falta de oportunidades, muitos estiveram fora da sala de aula por longos períodos. Esse programa possui relevante importância, uma vez que permite o retorno à escola de pessoas que possuem crenças, valores, ritmos de aprendizagem já formados de acordo com seu histórico de vida (RODRIGUES e PRESTES, 2013). A educação de jovens e adultos é apresentada como uma possibilidade de acesso a novos trabalhos, além de possibilitar a troca de experiências e atualizar o conhecimento (SOARES, 2007).

Alunos jovens e adultos trazem consigo maiores reflexões acerca do mundo. Isso faz com que essas pessoas possuam maiores habilidades e também dificuldades (OLIVEIRA, 1999). As aulas práticas aplicadas a esse público se apresentam como estratégias para superar os obstáculos que possam surgir no processo de aprendizagem. Portanto, servem para retomar conteúdos, anteriormente abordados, ampliando a visão sobre o tema. Além disso, por meio dessas aplicações, promove-se maior compreensão e se abre espaço para discussões durante a aula, permitindo que os alunos explorem suas ideias (LEITE, 2005). 
Volume, 14, n. 1, ano, 2018

Araújo (2014) relata a ausência de pesquisas voltadas para o Ensino de Ciências e de Biologia na Educação de Jovens e Adultos, enfatizando a necessidade de se pesquisar de modo sistêmico o processo de ensino aprendizagem para essa modalidade de ensino.

\section{OBJETIVOS}

Como os alunos da modalidade EJA ficaram longos períodos fora da sala de aula, o ensino precisa, então, atingir maiores significados e conversar com a vivência cotidiana desse sujeito. Partindo dessa ideia de convergência entre teoria e prática, o minicurso foi ofertado trazendo também a oportunidade do acesso ao laboratório e ao método científico. Entendendo a necessidade de um recurso metodológico eficaz no processo de ensino aprendizagem, objetivouse tornar possível o acesso às aulas práticas na forma de minicurso respeitando a ementa de Biologia do curso, desempenhando funções inovadoras envolvidas na construção de conhecimento científico. Assim, buscou alcançar especificamente:

- Maior facilidade na assimilação do conteúdo pelos alunos a partir de aulas interessantes, que despertem a curiosidade, observada a evidência da necessidade de uma aprendizagem mais dinâmica e voltada para os desejos da sociedade (ALEXANDRE, 2010);

- Participação dos alunos e interação entre os colegas, visto que são condições necessárias à construção de significados (SILVA, 2012);

- Avaliar o tempo de evasão escolar dos discentes, bem como os fatores de motivação e desmotivação da vida escolar desses estudantes.

\section{MATERIAL E MÉTODOS}

O referido minicurso se fundamentou, de forma qualitativa, uma vez que a observação do experimento, bem como do método, foram de fundamental importância para a discussão e avaliação da aprendizagem. O total de inscritos foi de oito alunos do Módulo IV do curso PROEJA Administração do Instituto Federal Goiano - Campus Rio Verde. O evento ocorreu no Laboratório de Ecofisiologia da instituição com carga horária total foi de duas horas. O laboratório, bem como equipamentos e roteiros, foram preparados previamente e colocados à disposição dos alunos. 
Volume, 14, n. 1, ano, 2018

A abordagem teórica teve como escopo o objetivo de fornecer a base necessária para a compreensão das atividades práticas, bem como subsidiar posterior discussão dos dados observados. Nessa etapa, foi ministrado aos alunos, uma aula sobre fotossíntese, abordando especificamente a visão geral sobre: fotossíntese, absorção luminosa, etapas da fotossíntese e fatores que influenciam a velocidade da fotossíntese.

A abordagem teórica utilizada está ancorada no livro didático específico para o Ensino Médio de Linhares e Gewandsznajder (2013). Para a abordagem prática, foi utilizado como referência o manual de aulas práticas de Fisiologia Vegetal de Maestri et al (1998), tendo adaptada a sua linguagem para facilitar a compreensão dos discentes. Os alunos participaram da preparação das lâminas com tecido de Elodea canadensis e puderam identificar suas estruturas no microscópio (Figura 1A). Com isso, foi possível dar significado à teoria, tornando mais próximos e palpáveis conceitos antes vistos apenas em livros.

Para a prática seguinte, os alunos foram divididos em dois grupos. O primeiro grupo fez a observação das hastes de E. canadensis apenas em água destilada e exposta à luz. O segundo grupo observou as hastes com a adição de bicarbonato de sódio a 1\% (Figura 1B). Essas observações ocorreram simultaneamente e com tempo cronometrado para que, posteriormente, fosse possível estabelecer discussão com base na teoria explicitada e a respeito das divergências de resultados.

Os certificados de participação foram expedidos pela instituição e entregues em outro momento. Nesse ato, os discentes responderam também a um questionário, elaborado para que avaliassem o minicurso e trouxessem informações relevantes à aprendizagem, período de evasão escolar, fatores de motivação e desmotivação da permanência no âmbito escolar e importância das aulas práticas. O questionário resguardou o anonimato de cada discente que se dispôs a responder, sendo utilizado inteiramente para a finalidade estatística. 
Volume, 14, n. 1, ano, 2018
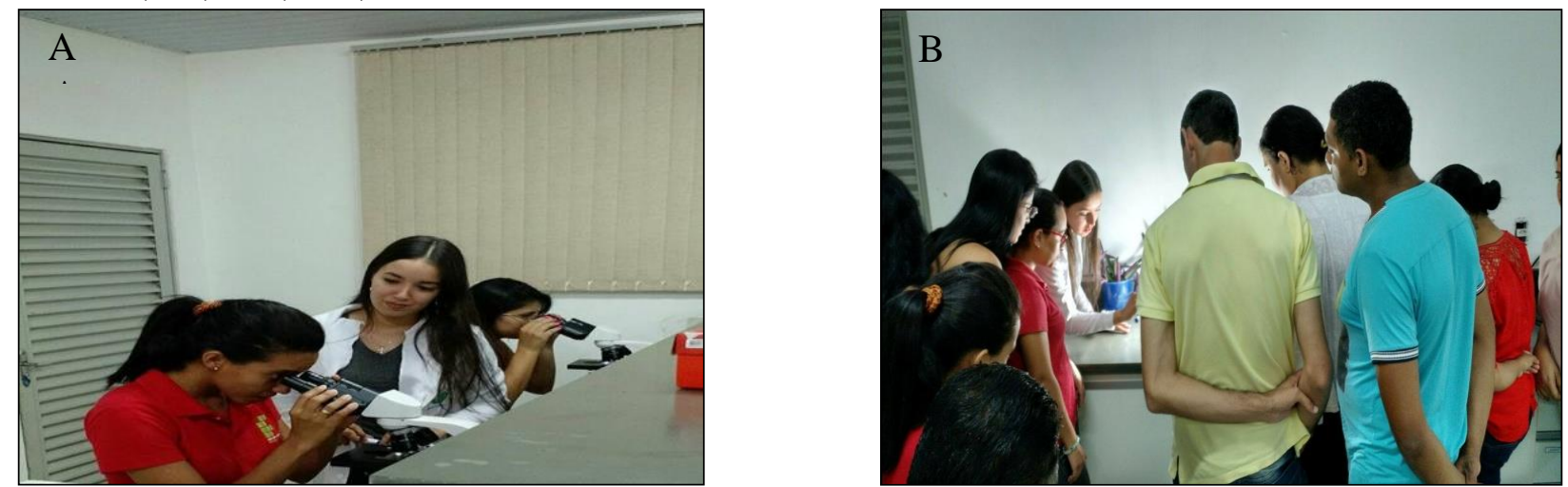

Figura 1: Abordagem prática: (A) observação da estrutura celular de Elodea canadensis em microscópio óptico; (B) fotossíntese com ênfase no fator luz e utilização de dióxido de carbônico.

\section{REVISÃO BIBLIOGRÁFICA}

O PROEJA propicia condições educacionais oportunas para jovens e adultos que não finalizaram o ensino médio e nem ao menos algum curso que os capacite profissionalmente (MOURA e HENRIQUE, 2012). Essa modalidade de ensino, que integra educação básica e técnica oferece, além das aprendizagens base, também a capacitação para o mercado de trabalho, que nos dias atuais apresenta-se muito competitivo.

Os alunos atendidos pela Educação de Jovens e Adultos consistem em pessoas que não tiveram oportunidades de estudar no tempo previsto, por enfrentar obstáculos durante a vida, principalmente na renda familiar, mas que conseguem voltar aos estudos com intenção de alcançar seus objetivos (ANDRADE, 2015).

A evasão escolar compreende um gargalo educacional brasileiro, mas tem sido parcialmente contornada pelas políticas públicas que abrangem a educação de modo geral (BORJA, 2014). Na visão escolar, a causa da evasão está relacionada a aspectos externos à escola, como a desestruturação familiar influencia o abandono nos estudos. Já na ótica dos responsáveis, as escolhas de amizades dos filhos influenciam a necessidade de se ausentarem (NETO, 2010). Para os alunos, de modo geral, esse abandono do espaço escolar ocorre devido às questões familiares, bem como, a necessidade do emprego imediato para complementar a renda da família e aos fatores internos à escola, como desentendimentos, desrespeitos e sentimentos de exclusão (FREITAG, 2003). 
Volume, 14, n. 1, ano, 2018

De acordo com Santos (2003), o público pouco escolarizado, devido à falta de oportunidades de acesso ou reintrodução no ensino, traz em sua bagagem sentimentos de inferioridade e marcas de maus resultados na escola. A dificuldade no processo de aprendizagem pode ser resultado de episódios de violência, porque o aluno não atendeu às expectativas, o que os exclui da escola. Muitos alunos também evadem devido ao trabalho infantil, já que precisam, desde cedo, ajudar ou assumir as despesas de casa (SANTOS, 2003).

A Educação de Jovens e Adultos oferece oportunidade ao aluno para recuperar seu potencial, porém o tempo fora da sala de aula se torna um desafio ainda maior para esse público enfrentar. As cobranças no mercado de trabalho, o avanço da tecnologia e o sentimento de exclusão social são fatores limitantes na conclusão de escolaridade (ANDRADE, 2015).

A motivação dos alunos em continuar os estudos ocorre em razão da grande procura de mão de obra qualificada do mercado de trabalho (SANTOS, 2013), além da expectativa em progredir nos níveis de conhecimento e o desejo da realização pessoal (SOGLIA e SANTOS, 2012). Retornando aos estudos, os alunos buscam um espaço de mudança para a emancipação social e atribuição de novos campos para o conhecimento (SANTOS, 2013).

As aulas práticas de laboratório podem contribuir no processo de obtenção de novos conhecimentos, facilitando a absorção de conteúdo, rejeitando-se a ideia de apenas oferecer uma ilustração de conteúdos visto na teoria (CAPELETTO, 1992). Além disso, essa proposta também promove a interação entre os alunos, proporcionando construção de conhecimentos científicos (SANTOS, 2011).

As atividades experimentais são imprescindíveis e indispensáveis quando se vinculam a uma metodologia apropriada, a partir de discussão e análise do conteúdo estudado (GIOPPO, 1998). O interesse e entusiasmo dos alunos nas aulas práticas beneficiam o esforço dos docentes (KRASILCHIK, 2008).

\section{RESULTADOS E DISCUSSÃO}

Para Cunha (2008), à primeira vista, a relação pedagógica está pautada na escolha de um bom método de ensino e em um planejamento adequado das matérias, além de conhecimento das competências intelectuais dos aprendizes. Nessa via, os alunos tiveram liberdade de realizar 


\section{REFLECILAIS}

GRADUACAO/POS-GRADUAC,AO EM EDUCAC, AO

UFG/REJ

Volume, 14, n. 1, ano, 2018

perguntas, sendo feitas analogias durante a aula, de modo a aproximar-lhes de suas realidades. A educação, na prática, precisa ir além de ministrar uma boa aula, então se procurou enfatizar, não somente a busca pelo referencial teórico e pelo método, mas também a preocupação com a individualidade do aluno.

Ficou evidenciado que o que foi falado na abordagem teórica pôde ser visto com clareza na atividade prática. De acordo com Vigotski (1998), a conversão entre fala e atividade prática constitui momentos de maior significado no curso do desenvolvimento intelectual.

Foram adquiridas competências quanto ao manuseio dos equipamentos, conforme ilustra a tabela 1. Além disso, foi possível identificar o interesse, participação e curiosidade a respeito das práticas e dos fenômenos observados, pois, de acordo com Silva et al (2011), ao manusear equipamentos de laboratório, há maior compreensão dos fenômenos biológicos. Isso permite que o aluno tenha maior assimilação de conteúdos considerados de difícil entendimento, já que estão muitas vezes restritos ao livro didático.

Tabela 1: Relação entre teoria, prática e competências adquiridas.

\section{Conteúdos abordados} na teoria

Processos observados

Célula vegetal.

Fotossíntese: visão geral.

Etapas da fotossíntese e absorção de luz.

Fator luz.

Fator dióxido de carbono.

Equação geral com ênfase na formação de carboidratos.
Observação dos cloroplastos.

Liberação de moléculas de oxigênio em forma de bolhas, quando exposto apenas à luz.

Aumento na liberação de bolhas, quando exposto à luz e ao bicarbonato de sódio.

Ênfase em fontes e drenos da planta.

\section{Competências adquiridas}

Preparação das lâminas.

Manuseio do microscópio.

Dosagem correta de substâncias e manuseio de vidrarias.

$$
\begin{aligned}
& \text { Valorização do trabalho } \\
& \text { coletivo ao observar e } \\
& \text { quantificar os dados. }
\end{aligned}
$$

Contextualização do conteúdo com a realidade do discente. 
Volume, 14, n. 1, ano, 2018

Kozow (2013) afirma que o PROEJA é uma forma de ensino diferenciada, para a qual, além de conhecimento, requer-se de boa vontade, uma vez que é preciso propiciar aos discentes prazer em voltar a estudar, valorizar suas experiências, cabendo ao docente à tarefa de inventar e reinventar a sua prática.

O questionário foi aplicado posteriormente com objetivo de verificar a eficiência das aulas práticas e avaliação do minicurso, além de conhecer o perfil dos alunos e tempo de evasão escolar antes do ingresso no curso PROEJA (Figura 2).

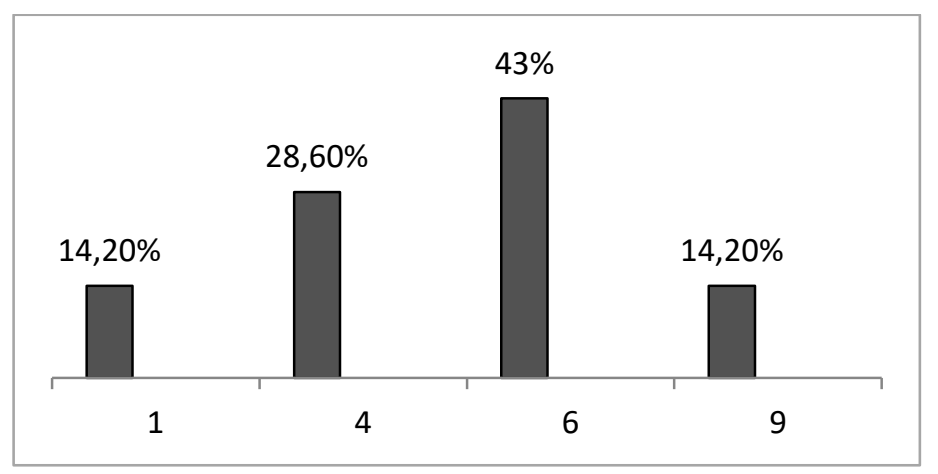

Figura 2: Relação entre tempo de evasão escolar, em anos, e percentual de alunos.

A média de tempo em que estiveram fora da sala de aula foi de 5 anos, sendo que o discente que permaneceu mais tempo fora da escola, o fez por nove anos, enquanto o discente que permaneceu menos tempo sem estudar ficou fora um ano.

Pensando nos fatores que motivaram esses alunos a procurarem a escola, mais especificamente o curso PROEJA integrado ao técnico em Administração, foram questionados quanto às suas motivações (Figura 3A). A questão admitiu múltipla escolha, sendo que a principal motivação foi a espontânea vontade, evidenciando a realização pessoal, com 71,4\% das marcações, seguida de capacitação para o mercado de trabalho e progredir no emprego que já possuíam antes do ingresso.

Lioncio (2009) encontrou dados semelhantes, entretanto em sua pesquisa os estudantes da Educação de Jovens e Adultos admitiram que a necessidade de aperfeiçoamento para o mercado de trabalho havia sido a principal motivação, seguida pela realização pessoal. 
Volume, 14, n. 1, ano, 2018

Considerando a importância da permanência dos discentes na escola, esses estudantes foram questionados sobre os obstáculos que enfrentavam para dar continuidade (Figura 3B) aos estudos, uma vez que esses empecilhos podem ser fatores limitantes na conclusão do curso, visto a vulnerabilidade e o risco de evasão escolar. Essa questão admitiu, também, múltipla escolha e a opção mais escolhida, com 50\% das respostas, foi conciliar o trabalho e os estudos, seguida pela distância, pois há alunos que moram em outras cidades da região, e questões financeiras. Em pesquisas semelhantes, foram evidenciados também outros fatores, como a dificuldade de aprendizagem, falta de motivação e falta de apoio familiar (LIONCIO, 2009).

Os alunos foram questionados também quanto à importância das aulas práticas (Figura 3C), a fim de avaliar aspectos positivos e negativos no processo de ensino-aprendizagem. Essa questão admitiu mais de uma resposta por parte dos discentes.

Ficou evidente que esses alunos notaram a melhor absorção do conteúdo visto em teoria $(62,5 \%)$. Essa resposta pode ter sido mais marcada devido a abordagem teórica ter sido seguida pela prática. Lira (2013) afirma que a experimentação no ensino de Biologia na modalidade EJA é extremamente importante, possibilitando melhor entendimento dos fatos e construção do saber científico, além de tornar possível a diversificação das aulas e promover contato palpável com o objeto de estudo. Esse aspecto esteve entre as respostas dadas pelos discentes quando questionados sobre a importância do material utilizado no laboratório (Figura 3D), muito embora tenha sido evidenciado que a participação e interação com a turma lhes chamou mais atenção, totalizando 44,4\% das respostas a essa questão.

No questionário havia também uma questão que abordava o aumento ou não da absorção do conteúdo e os estudantes foram unânimes ao responder que sim, aulas práticas auxiliam nesse processo. Tiveram liberdade de responder também, de forma discursiva, essa questão. Nas respostas, relacionaram as aulas práticas com "quebrar a rotina de sala de aula" e "mais clareza de entendimento".

Tendo como opções "Bom", "Razoável” ou "Ruim", todos avaliaram as atividades práticas (minicurso desenvolvido no laboratório), como "Bom”. 
Volume, 14, n. 1, ano, 2018
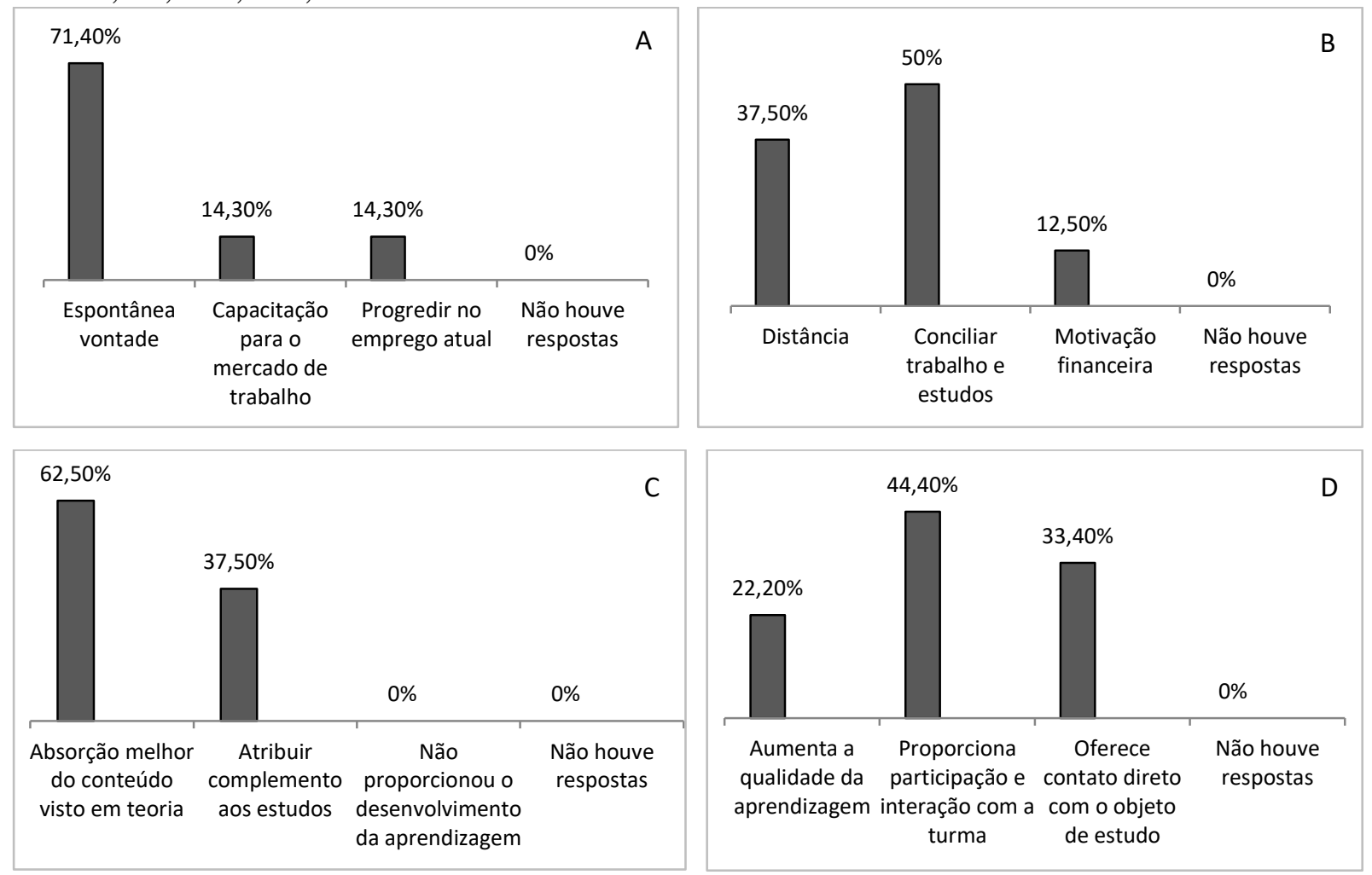

Figura 3: Respostas dos alunos quando questionados sobre: (A) motivação em procurar o curso PROEJA Técnico em Administração e percentual das opções marcadas; (B) Obstáculo que enfrentavam em dar continuidade nos estudos, em percentual. Essa questão admitiu mais de uma resposta; (C) Importância de aulas práticas, em percentual. Essa questão admitiu mais de uma resposta; (D) Pontos que os discentes consideravam mais importantes sobre os materiais utilizados no laboratório, em percentual. Essa questão admitiu mais de uma resposta.

\section{CONSIDERAÇÕES FINAIS}

O minicurso aplicado ao PROEJA se apresentou de forma positiva, visto que os alunos puderam observar, na prática, o que aprenderam na teoria. Foi uma experiência nova, ficando notável a satisfação que tiveram, demonstrada por meio de relatos de alguns alunos pelo desejo em aprofundar os seus conhecimentos na área. As aulas práticas promoveram maior absorção do conteúdo a partir da vivência, auxiliando no processo de socialização, sendo que para a realização dos experimentos e busca por dados, os discentes precisaram trabalhar em equipe. Essas práticas são, portanto, uma abordagem prazerosa do processo de ensinoaprendizagem e podem ser vistas como prática motivadora para a permanência de alunos Jovens e Adultos na sala de aula. 
Volume, 14, n. 1, ano, 2018

REFERENCIAS

ALEXANDRE, Sueli de Fátima. Aprendizagem e suas implicações no processo educativo. Iconoletras. Universidade Estadual de Goiás. v.5 p.41-60, julho, 2010.

ALMEIDA, J.S. Prática de Ensino e Estágio Supervisionado na Formação de Professores. Cad. Pesq., São Paulo, n.93, p.22-31, maio, 1995.

ALVES, Ruben. Entre a ciência e a sapiência: O dilema da educação. São Paulo: Loyola, 148p, 1999.

ANDRADE, N. Q. Educação De Jovens E Adultos: a necessidade de retornar à escola. Revista Eventos Pedagógicos Articulação universidade e escola nas ações do ensino de matemática e ciências v.6, n.2 (15. ed.), número regular, p. 190-199, jun./jul. 2015.

ARAÚJO, Simone Paixão; CARNEIRO, Maria Helena da Silva. Educação de jovens e adultos no ensino médio, uma revisão bibliográfica sobre o ensino de Ciências. Ciências e cognição. V. 19 (1), p. 96-104. 2014.

BORJA, I. M. F. S. Evasão escolar: desigualdade e exclusão social. Revista Liberato, Novo Hamburgo, v. 15, n. 23, p. 01-104, jan./jun. 2014.

BORSSOI, B. L. O Estágio Na Formação Docente: da teoria a prática, ação-reflexão. $1^{\circ}$ SIMPÓSIO NACIONAL DE EDUCAÇÃO E XX SEMANA DA PEDAGOGIA. Cascavel - PR: Unioeste, 2008.

BRASIL, Presidência da República. Decreto No 5.840, De 13 De Julho De 2006.

CAPELETTO, A. Biologia e Educação ambiental: Roteiros de trabalho. Editora Ática, 1992.

CUNHA, M. V. Psicologia da educação. Rio de Janeiro: editora lamparina, 2008.

DEMO, Pedro. Educar pela pesquisa. Campinas: Autores associados, 1996.

FREITAG, B. Escola, Estado e sociedade. 4. ed. São Paulo: Moraes, 2003.

GIOPPO, C.; SCHEFFER, E. W. O.; NEVES, M. C. D. O ensino experimental na escola fundamental: uma reflexão de caso no Paraná. Educar, n. 14, p. 39 - 57. 1998.

KRASILCHIK, M. Prática de Ensino de Biologia. São Paulo: Edusp, 2008. 
Volume, 14, n. 1, ano, 2018

KOZOW, Lúcia. Proeja: Prática Docente Diferenciada. CAMINHANDO COM O PROEJA: reflexões, desafios, atitudes. IFAL, v. 1, n.1, p.103-109. 2013.

LEITE, Adriana Cristina Souza; SILVA, Pollyana Alves Borges; VAZ, Ana Cristina Ribeiro. A importância das aulas práticas para alunos jovens e adultos: uma abordagem investigativa sobre a percepção dos alunos do PROEF II. Ensaio: 2005. Disponível em: <http://www.portal.fae.ufmg.br/seer/index.php/ensaio/article/viewFile/98/147>. Acesso em janeiro de 2016.

LINHARES, Sérgio; GEWANDSZNAJDER, Fernando. Biologia Hoje. 2 ed. São Paulo. Ática, 2013.

LIRA, Luzia dos Santos. A Importância da Prática Experimental no Ensino de Biologia na Educação de Jovens e Adultos. Universidade Federal da Paraíba. 2013.

LIONCIO, Mayra de Paula. Principais motivadores da evasão escolar no Ensino Médio EJA. Instituto Federal de Educação, Ciência e Tecnologia De São Paulo. 2009.

MOURA, D. H.; HENRIQUE, A. L. S. Proeja: Entre desafios e possibilidades. Holos, Ano 28, v. 2, p. 114 - 129. 2012.

MAESTRI ET AL. Fisiologia vegetal: Exercícios Práticos. Viçosa. Editora UFV, 1998.

NETO, A. R. M.; et al. Evasão escolar e desinteresse dos alunos nas aulas de educação física. Pensar a Prática, Goiânia, v. 13, n. 2, p. 115, maio/ago. 2010.

OLIVEIRA, M. K. Jovens e adultos como sujeitos de ensino e aprendizagem. Revista brasileira de educação, n.12, p.59-73, set/out/nov/dez. 1999.

RODRIGUES, Ana Cláudia da Silva; PRESTES, Emília Maria da Trindade. Avaliação Do Proeja Mediante A (Re) Construção Da Identidade E Reconhecimento Dos Educandos. Revista Lugares de Educação, Bananeiras/PB, v. 3, n. 7, p. 49-68. Edição Especial. Dez., 2013

SANTOS, C. P; ARRUDA, R. A. A visão dos alunos da educação de jovens e adultos sobre a escola. Revista Eventos Pedagógicos v.4, n.2, p. 31 - 40, ago. - dez. 2013.

SANTOS, J. N dos. Recursos pedagógicos: o fazer pedagógico para um olhar teórico prático. In: SANTOS, J. N dos (Org.). Ensinar ciências: reflexões sobre a prática pedagógica no contexto educacional. Blumenau: Nova Letra, 2011. 
Volume, 14, n. 1, ano, 2018

SANTOS, M. L. L. Educação de jovens e adultos: marcas da violência na produção poética. Passo Fundo: UPF. 2003, p.74.

SILVA, Danito Garcia da. et al. Trajetórias de Aprendizagem, Participação e Interação: Possibilidades dos Relatórios do Moodle. SIED - Simpósio Internacional de Educação a Distância. UFSCAR, 2012.

SILVA, R. F. et al. O ensino de biologia e as atividades experimentais: uma aposta motivacional para aprendizagem. ENCONTRO NACIONAL DE PESQUISA EM EDUCAÇÃO EM CIÊNCIAS, 8. Campinas, 2011.

SOARES, Maria Aparecida Fontes. Perfil Do Aluno da EJA / Médio na Escola Dr. Alfredo Pessoa de Lima. Bananeiras, 2007. Disponível em: http://portal.mec.gov.br/setec/arquivos/pdf3/tcc_perfil.pdf. Acesso em março de 2016.

SOGLIA, I. S., SANTOS, C. S. P. Educação de Jovens e Adultos: expectativas e dificuldades. 2012.

VIGOTSKI, L. S. A formação social da mente: o desenvolvimento dos processos psicológicos superiores. 6. ed. São Paulo: Martins Fontes, 1998. 